\title{
Efficacy of Isometamidium in Combination with Verapamil, Chlorpromazine or Sodium-ethylenediaminetetra-acetic Acid in Treatment of Experimental Diminazene Aceturate-resistant Strain of Trypanosoma brucei brucei Infection in Rats
}

\author{
*Chukwudi, I. C., Omemgboji, O.C. and Anene, B.M.
}

Department of Veterinary Medicine, Faculty of Veterinary Medicine, University of Nigeria, Nsukka Enugu State, Nigeria.

\begin{abstract}
*Author for Correspondence: ijeoma.adieme@unn.edu.ng
ABSTRACT

This study investigated the efficacy of different chemotherapeutic regimes in the treatment of rats experimentally infected with diminazene aceturate-resistant strain Trypanosoma brucei brucei. Thirty Sprague Dawley male rats used for the study were randomly assigned to six groups of five rats each as follows: group A-uninfected untreated (negative control), group Binfected and untreated (positive control), groups C-F were infected and treated with $1.0 \mathrm{mg} / \mathrm{kg}$ isometamidum chloride, administered intramuscularly on day 11 post-infection. However, rats in groups $\mathrm{D}, \mathrm{E}$ and $\mathrm{F}$ received further treatments with $700 \mathrm{mg} / \mathrm{kg}$ sodium-ethylenediamine tetra-acetic acid, $0.4 \mathrm{mg} / \mathrm{kg}$ verapamil and $3 \mathrm{mg} / \mathrm{kg}$ chlorpromazine, respectively, administered orally for four days. Clearance of parasite post-treatment (PT), mortality PT, relapse parasitaemia post-clearance, body weight change, rectal temperature, packed cell volume (PCV), haemoglobin (HB) concentration and red blood cell count (RBC) were determined during the experiment. Result showed parasite clearance PT of $100 \%$ in groups D and E, $80 \%$ in group F and $20 \%$ in group C by 24 hours PT. The infection relapsed on day 35 PT in $40 \%$ of rats in group C, on day 37 PT in $20 \%$ of rats in group F and lastly $20 \%$ of rats in groups D and E on day 39 PT. Rats that received drug combination showed marginal improvement in erythrocytic parameters analysed when compared with those treatment with isometamidium alone. Combination therapy showed faster clearance of parasite from the blood and also prolonged relapse post-clearance, thus had a better promising efficacy when compared to using isometamiduim chloride alone.
\end{abstract}

Keywords: Chlorpromazine, Diminazene aceturate-resistance; Isometamidium chloride; Sodium-EDTA salt; Trypanosoma brucei brucei; Verapermil

\section{INTRODUCTION}

African trypanosomosis is a debilitating disease caused by a group of haemoflagellate protozoan parasites of the genus Trypanosoma and has continued to cause a major setback to livestock production in Nigeria despite attempts at its control. Trypanosomosis control in Africa relies mainly on chemotherapy and chemoprophylaxis using diminazene aceturate, homidium and isometamidium chloride (Sonibare et al., 2016). Diminazene resistance was reported to be widespread, which frustrated efforts to the control of the disease in livestock (Delespaux and de Koning, 2007). With the current challenges posed by existence of drug resistant strains of trypanosomes and increased incidence of toxicity, development of new antitrypanosomal drugs and or compound becomes a necessity (Onyeyili and Aliyoo, 2015; Sonibare et al., 2016). Effort towards this would however be limited by the expensive nature of developing and patenting new drugs, which discouraged pharmaceutical companies from developing new trypanocides for use in animals or humans (Geerts et al., 2001). There was therefore the need to explore ways of achieving the optimum results from use of the existing trypanocides (Abimbola et al., 2013).

Isometamidium chloride/hydrochloride has been used for both chemotherapy and chemoprophylaxis in livestock for over so many decades (Giordani et al., 2016). There were reports of development of multiple drug resistance to isometamidium and diminazene aceturate and this was a setback to the use of sanative pair in overcoming problem of drug resistance to a single drug (Mamoudou et al., 2008). It has been documented that drug resistance emerges when a genetic change, a mutation, deletion or amplification alters drug uptake, drug metabolism, drug-target interaction or drug efflux (Baker et al., 2013).

Sodium-ethylenediamine tetra-acetic acid (Na-EDTA) increases membrane permeability and enhances absorption of substances, such as molecules of isometamidium, into various cells through cell membranes, thereby potentiating their actions (Haque and Russell, 1974). Verapamil is a calcium channel blocker and has been used as inhibitor of 
drug efflux pump protein, such as P-glycoproteins in cell biology. Thus, verapamil limits the efflux of drugs from their sites of activity (Anene et al., 1996). Verapamil also has a resistance-reversing effect and was shown to inhibit chloroquine-resistance-transporter (CRT) thereby abolishing chloroquine resistance of Plasmodium falciparum (Malaria parasite) (Mier et al., 2018). Verapamil and chlorpromazine were effective in reversing resistance in neoplastic cells (Gottesman and Pasten, 1998) and malaria parasites (Oduola et al., 1998; Mier et al., 2018). In humans, treatment of malaria parasite infection was carried out using verapamil, in combination with other antimalaria drugs, where it limits the parasite cell's ability to expel the drugs outside its digestive vacuole (Ramirez and Villafuerte, 2004). Chlorpromazine is a tricyclic drug and was reported to have a reversal effect on resistant malaria parasite (Oduola et al., 1998).

Against the background on these reports, this study evaluated the efficacy of combinations of these agents with isometamidium in the treatment of experimental diminazene aceturate-resistant (DA-resistant) strain of Trypanosoma brucei brucei infection.

\section{MATERIALS AND METHODS}

\section{Ethical Statement}

All rats were handled according to the international guiding principles (NASA, 2008) and was approved by the Animal Ethics committee of the Faculty of Veterinary Medicine, University of Nigeria.

\section{Experimental Animals}

Thirty Sprague Dawley adult male albino rats weighing 140-200 $\mathrm{g}$ used for this study were procured from the breeding colony of the Department of Zoology, University of Nigeria, Nsukka. They were randomly assigned into six groups of 5 rats each and kept in their respective standard rat cages in the Laboratory Animal Unit of the Department of Veterinary Medicine. They were fed proprietary rat feed (Vital feeds ${ }^{\circledR}$ ), clean water was provided ad libitium; the rats were allowed to get acclimatized for two weeks. During this period, they were screened and confirmed to be free of blood parasites and were also dewormed with albendazole $\left(\right.$ Zolat $^{\circledR}$ ) at $7.5 \mathrm{mg} / \mathrm{kg}$ body weight.

\section{Trypanosomes (Diminazene Aceturate-resistant Strain)}

The Trypanosoma brucei brucei (T.b. brucei) used in this study was originally isolated from cattle presented to the abattoir in Nsukka, Enugu State. The parasites were identified morphologically (Soulsby, 1986) and by the blood incubation infectivity test (BII'I') (Rickman and Robson, 1970). The parasite was confirmed and established to be a DA- resistant strain using the standardized test described by Eisler et al. (2001). The trypanosomal organisms were subsequently maintained in mice in the Department of Veterinary Entomology and Parasitology, UNN from which donor rats were first infected.

\section{Infection of Experimental Rats}

Trypanosome infection of the donor rats was by intraperitoneal inoculation and pre-patent period of 3-5 days was recorded and the parasitaemia level on the day the experimental rats were infected was $5.0 \times 10^{8} T . \quad b$. brucei $/ \mathrm{ml}$. Infected blood from the donor rats was obtained from the retrobulbar plexus via the median canthus of the eye into an EDTA sample bottles. This infected blood was diluted with normal saline. The experimental rats were then infected with an inoculum containing $1 \times 10^{6}$ trypanosomes suspended in $0.25 \mathrm{ml}$ normal saline via intra-peritoneal route.

\section{Experimental Drugs}

Three drugs and a compound used for this experiment were: isometamidiun chloride (MERIAL, France), verapamil (TEVA UK Ltd) (Eagle Company Korea), chlorpromazine (Wuhan Grand Pharmacy, Wuhan China) and SodiumEDTA (BDH Chemicals Company ltd, Poole England). Working solutions of these drugs (except isometamidium chloride) were prepared immediately before use, by appropriate dilution in distilled deionized water (DDW) and sterilized by filtration through a $0.22 \mu \mathrm{m}$ pore-size filter.

\section{Experimental Design}

The thirty Sprague Dawley albino rats were randomly assigned to six groups (A-F) of five rats each. All the rats in groups B-F were each, infected with $1 \times 10^{6} T$. b. brucei organisms via intra-peritoneal route, while rats in group A were left uninfected and thus served as negative control. All the rats in groups C-F were treated with $1.0 \mathrm{mg} / \mathrm{kg}$ isometamidium chloride intramuscularly 11 days postinfection (PI). However, rats in groups D, E and $\mathrm{F}$ received additional treatments with Sodium-EDTA at $700 \mathrm{mg} / \mathrm{kg}$, verapamil at $0.4 \mathrm{mg} / \mathrm{kg}$ and chlorpromazine at $3 \mathrm{mg} / \mathrm{kg}$ body weight, respectively, orally for 4 days which commenced on day 11 PI. The rats in group B were left untreated as positive control.

\section{Parameters for Assessing Efficacy of Treatments}

The efficacy of treatments was assessed using the following: parasite detection (clearance of parasite post-treatment and relapse parasitaemia post-clearance) by wet mount method using a light microscope (x400 objective) to observe the wriggling movement of the trypanosomes between the blood cells (Boyt, 1984), body weight changes by placing rats on sensitive weighing scale, rectal temperature by insertion of aseptic clinical thermometer manually into the rectum of the rats, packed cell volume (Dacie and Lewis, 1999), red blood cell count and haemoglobin concentration (Schalm et al., 1975). The rats were also observed throughout the experiment for clinical signs of trypanosomosis.

\section{Statistical Analyses}

Data obtained was computed into means and analysed using one-way analysis of variance (ANOVA). The means were separated at post hoc using Duncan's Multiple Range test (Duncan, 1996) at 95\% confidence interval. 


\section{RESULTS}

Onset of Parasitaemia: Trypanosome parasites were seen in the blood of all the infected rats 5 days post-infection (PI) and the level of parasitaemia progressively increased until rats in groups C-F were treated on day 11 PI (Table 1).

Clearance of Parasitaemia Post-treatment (PT): There was complete clearance of parasites from the blood of $20 \%$ of group $\mathrm{C}$ rats; $80 \%$ of group $\mathrm{F}$ rats and $100 \%$ of group D and E rats by 24 hours PT. By 72 hours PT, the blood of all treated rats of the infected groups had become 100\% aparasitaemic, while the positive control (group B) rats remained parasitaemic and were euthanized on day 42 PI (Table 1).

Relapse Parasitaemia Post-clearance: Relapse infection occurred in $40 \%$ of group $\mathrm{C}$ rats on day $35 \mathrm{PT}$, and then in $20 \%$ of groups $\mathrm{F}$ rats on day 37 PT. By day 39 PT, 20\%, each, of groups D and $\mathrm{E}$ rats had relapse infections, while
$60 \%$ and $40 \%$ of group $\mathrm{C}$ and $\mathrm{F}$ rats, respectively, had the relapse infections. By the end of the experiment, relapse infection was recorded in at least $40 \%$ of the treated groups $\mathrm{C}, \mathrm{D}, \mathrm{E}$ and $\mathrm{F}$ rats, irrespective of the combinations, with a range of $40-100 \%$ in the various groups (Table 1 ).

Survival Post-infection: No mortality was recorded among the treated groups. Mortality was recorded in $40 \%$ of rats in group B by day 35 PI which led to the euthanasia of the remaining rats by day 42 PI (Table 1 ).

Clinical Signs: The following clinical signs were observed: weakness, cuddling, depression, decreased feed intake and pale mucous membrane. These clinical signs gradually disappeared following treatment of the rats in groups $\mathrm{C}-\mathrm{F}$, while the clinical signs remained in the positive control (group B) in addition to enlarged abdomen and death. These clinical signs gradually returned with relapse infection in the treated groups.

Table 1: Parasitaemia, Clearance and Relapse Infection Post-treament in Rats Infected with DA-resistant $T . b$. bruce $i$ and Treated with Isometamidium in Combination with either Na- EDTA, Verapamil or Chlorpromazine

\begin{tabular}{llllll}
\hline Days Post-Infection & Group B & Group C & Group D & Group E & Group F \\
\hline $\mathbf{0}$ & $0 / 5$ & $0 / 5$ & $0 / 5$ & $0 / 5$ & $0 / 5$ \\
\hline $\mathbf{3}^{*}$ & $0 / 5$ & $1 / 5$ & $2 / 5$ & $0 / 5$ & $1 / 5$ \\
\hline $\mathbf{5}$ & $5 / 5$ & $5 / 5$ & $5 / 5$ & $5 / 5$ & $5 / 5$ \\
\hline $\mathbf{7}$ & $5 / 5$ & $5 / 5$ & $5 / 5$ & $5 / 5$ & $5 / 5$ \\
\hline $\mathbf{9}$ & $5 / 5$ & $5 / 5$ & $5 / 5$ & $5 / 5$ & $5 / 5$ \\
\hline $\mathbf{1 1 * *}$ & $5 / 5$ & $5 / 5$ & $5 / 5$ & $5 / 5$ & $5 / 5$ \\
\hline $\mathbf{1 2}$ & $5 / 5$ & $4 / 5$ & $0 / 5$ & $0 / 5$ & $1 / 5$ \\
\hline $\mathbf{1 4}$ & $5 / 5$ & $0 / 5$ & $0 / 5$ & $0 / 5$ & $0 / 5$ \\
\hline $\mathbf{2 1}$ & $5 / 5$ & $0 / 5$ & $0 / 5$ & $0 / 5$ & $0 / 5$ \\
\hline $\mathbf{3 5}$ & $3 / 3$ & $0 / 5$ & $0 / 5$ & $0 / 5$ & $0 / 5$ \\
\hline $\mathbf{4 6} * * *$ & $2 / 5$ & $0 / 5$ & $0 / 5$ & $0 / 5$ \\
\hline $\mathbf{4 8}$ & & $2 / 5$ & $0 / 5$ & $0 / 5$ & $1 / 5$ \\
\hline $\mathbf{5 0}$ & & $3 / 5$ & $1 / 5$ & $1 / 5$ & $2 / 5$ \\
\hline $\mathbf{5 2}$ & & $3 / 5$ & $1 / 5$ & $1 / 5$ & $2 / 5$ \\
\hline $\mathbf{5 4}$ & & $3 / 5$ & $2 / 5$ & $2 / 5$ & $2 / 5$ \\
\hline $\mathbf{6 0}$ & & $4 / 5$ & $2 / 5$ & $2 / 5$ & $2 / 5$ \\
\hline $\mathbf{6 7}$ & & $5 / 5$ & $2 / 5$ & $2 / 5$ & $2 / 5$ \\
\hline $\mathbf{7 4}$ & & $5 / 5$ & $2 / 5$ & $2 / 5$ & $3 / 5$ \\
\hline $\mathbf{8 5}$ & & $5 / 5$ & $2 / 5$ & $2 / 5$ & $3 / 5$ \\
\hline
\end{tabular}

*Commencement of parasitaemia; $* *$ Treatment and parasite clearance, $* * *$ Commencement of relapse infection Numerator: Number of parasitaemic animal in the group; Denominator: total number of rats surviving in the group.

Group B- infected, untreated (positive control); C- Infected, treated with $1 \mathrm{mg} / \mathrm{kg} \mathrm{ISM}$; D- Infected, treated with $1 \mathrm{mg} / \mathrm{kg}$ ISM $+700 \mathrm{mg} / \mathrm{kg}$ Na-EDTA; E- Infected, treated with $1 \mathrm{mg} / \mathrm{kg}$ ISM $+0.4 \mathrm{mg} / \mathrm{kg}$ Verapamil; F- Infected, treated with $1 \mathrm{mg} / \mathrm{kg}$ ISM $+3 \mathrm{mg} / \mathrm{kg}$ Chlorpromazine.

Proportional Body Weight Change: There was a significant decrease $(\mathrm{P}<0.05)$ in the mean proportional weight change in rats of group $\mathrm{B}$ when compared with corresponding values in other infected groups and the negative control group from day 21 PI until they were euthanized (Figure 1).

Rectal Temperature (RT): The mean RT of all infected rats (groups $\mathrm{B}, \mathrm{C}, \mathrm{D}, \mathrm{E}$ and $\mathrm{F})$ were significantly higher $(\mathrm{P}<$ 0.05 ) on day seven PI (Figure 2). However, by day 21 (10 days PT), the mean RTs the treated groups $(\mathrm{C}, \mathrm{D}, \mathrm{E}$ and $\mathrm{F})$ were not statistically different from the negative control (group A) up to day $42 \mathrm{PI}$, while the positive control (group $\mathrm{B})$ continued to show a significant increase $(\mathrm{P}<0.05)$. There mean RT $(\mathrm{P}<0.05)$ was significantly higher in rats of groups $\mathrm{C}$ and $\mathrm{F}$ (day $49 \mathrm{P} 1$ ) and in groups $\mathrm{C}, \mathrm{D}, \mathrm{E}$ and $\mathrm{F}$ (day $63 \mathrm{PI}$ ) than in the negative control.

Packed Cell Volume (PCV): The mean PCV of rats in the infected groups was significantly lower $(\mathrm{P}<0.05)$ than the corresponding value in the negative control (group A) by day 7 PI (Figure 3). However, by day 28 PI (17 days PT) up to day 49 PI (day $38 \mathrm{PT}$ ), the mean PCV values of the treated groups $(\mathrm{C}, \mathrm{D}, \mathrm{E}$ and $\mathrm{F})$ were not statistically 
different from the corresponding value in negative control, while the mean PCV in the positive control (group B) continued to show significant decrease $(\mathrm{P}<0.05)$ up to when they were euthanized. There was a significantly lower $(\mathrm{P}<0.05)$ mean $\mathrm{PCV}$ in rats of groups $\mathrm{C}, \mathrm{E}$ and $\mathrm{F}$, on day
63, and groups $\mathrm{C}, \mathrm{D}$ and $\mathrm{F}$, on day 77, when compared with the negative control and other treated groups, and a significantly higher $(\mathrm{P}<0.05)$ mean $\mathrm{PCV}$ of rats in groups $\mathrm{D}, \mathrm{E}$ and $\mathrm{F}$ on day 84 when compared to group $\mathrm{C}$ (treated with ISM alone) and group A (negative control).

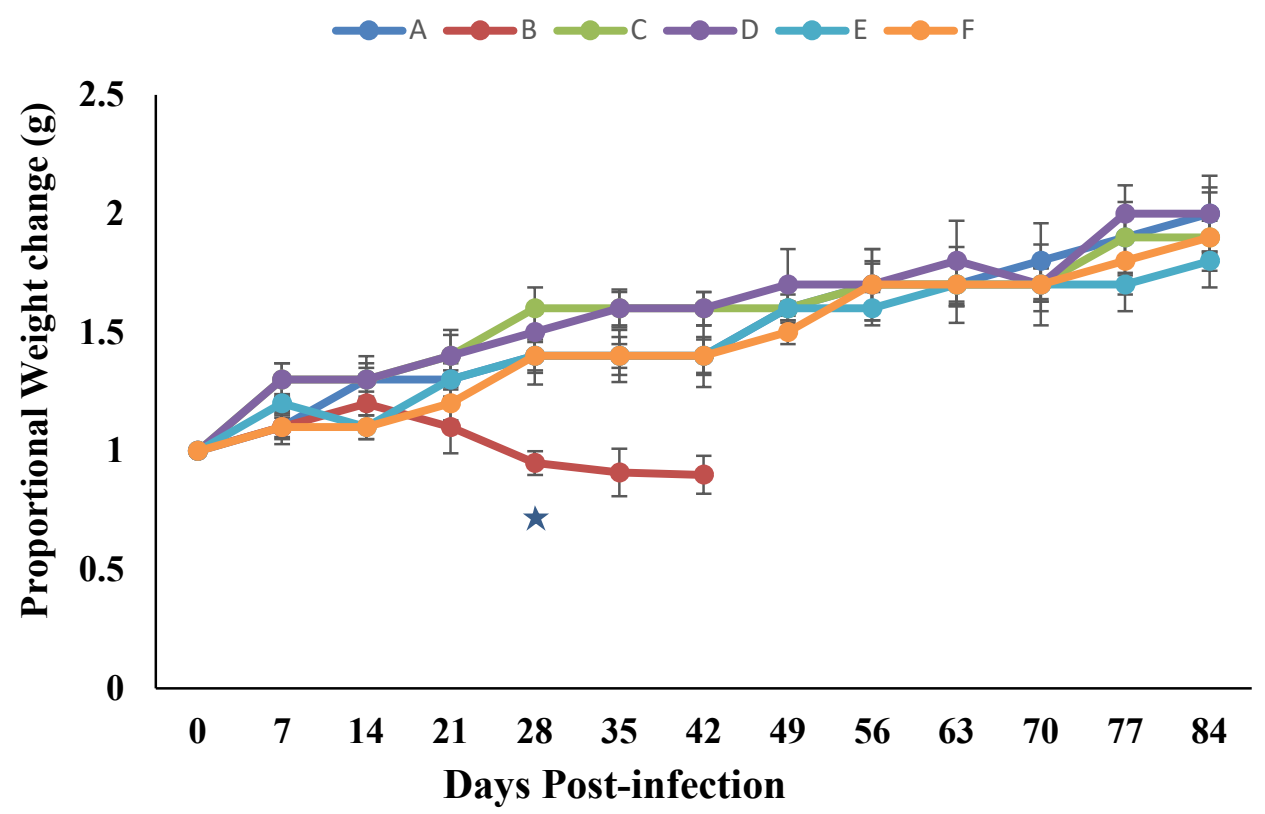

Figure 1: The mean $( \pm \mathrm{SEM})$ proportional body weight change $(\mathrm{g})$ of rats infected with DA-resistant $T$. b. brucei and treated with ISM alone and in combination with either Na-EDTA, verapamil or chlorpromazine. * significant at $\mathrm{p}>0.05$

A-uninfected, untreated (negative control); B-positive control; C-infected, treated with 1mg/kg ISM; D-infected, treated with $1 \mathrm{mg} / \mathrm{kg}$ ISM $+700 \mathrm{mg} / \mathrm{kg}$ Na-EDTA; E-infected, treated with $1 \mathrm{mg} / \mathrm{kg}$ ISM $+0.4 \mathrm{mg} / \mathrm{kg}$ verapamil; F-infected, treated with $1 \mathrm{mg} / \mathrm{kg}$ ISM $+3 \mathrm{mg} / \mathrm{kg}$ chlorpromazine

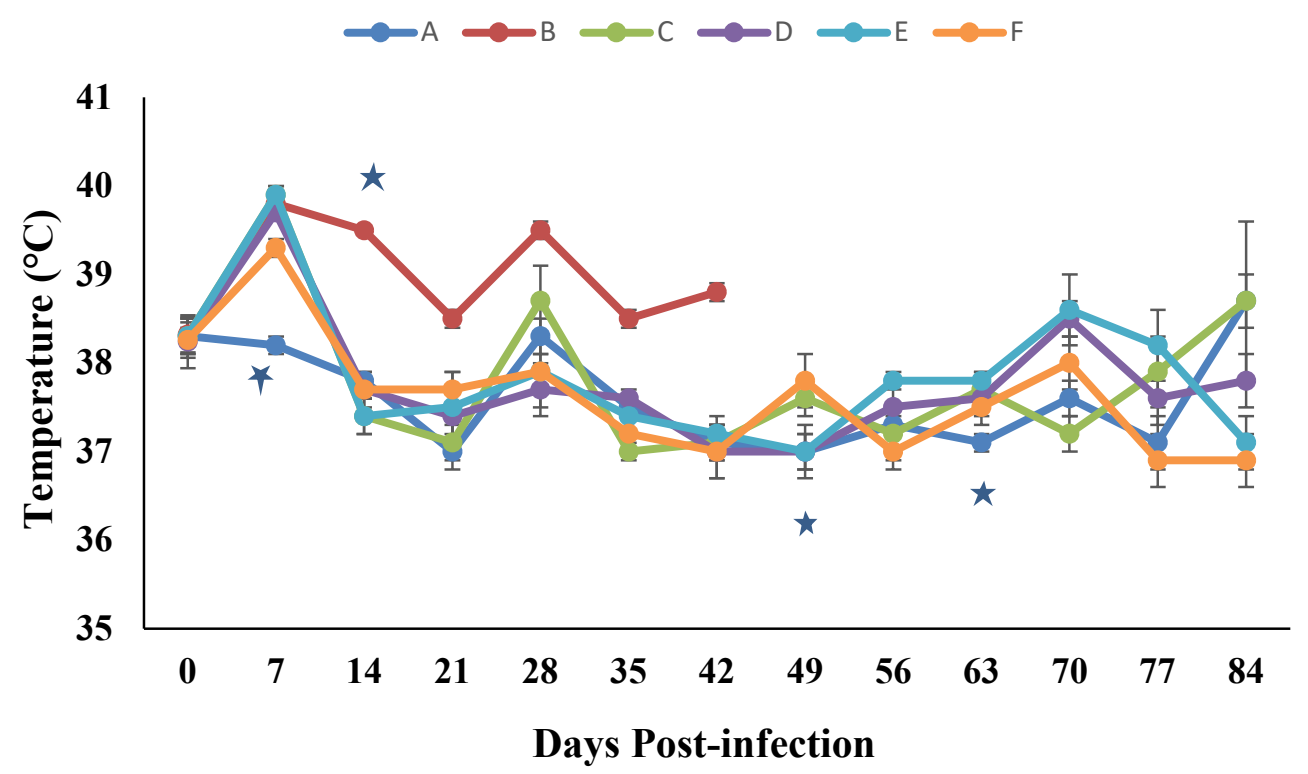

Figure 2: The mean $( \pm \mathrm{SEM})$ rectal temperature $\left({ }^{\circ} \mathrm{C}\right)$ of rats infected with DA-resistant strain $T$. b. brucei and treated with ISM alone and in combination with Na-EDTA, verapamil and chlorpromazine. * significant at $\mathrm{p}>0.05$

A-uninfected, untreated (negative control); B-positive control; C-infected, treated with 1mg/kg ISM; D-infected, treated with $1 \mathrm{mg} / \mathrm{kg} \mathrm{ISM}+700 \mathrm{mg} / \mathrm{kg}$ Na-EDTA; E-infected, treated with $1 \mathrm{mg} / \mathrm{kg}$ ISM $+0.4 \mathrm{mg} / \mathrm{kg}$ verapamil; F-infected, treated with $1 \mathrm{mg} / \mathrm{kg} \mathrm{ISM}+3 \mathrm{mg} / \mathrm{kg}$ chlorpromazine 


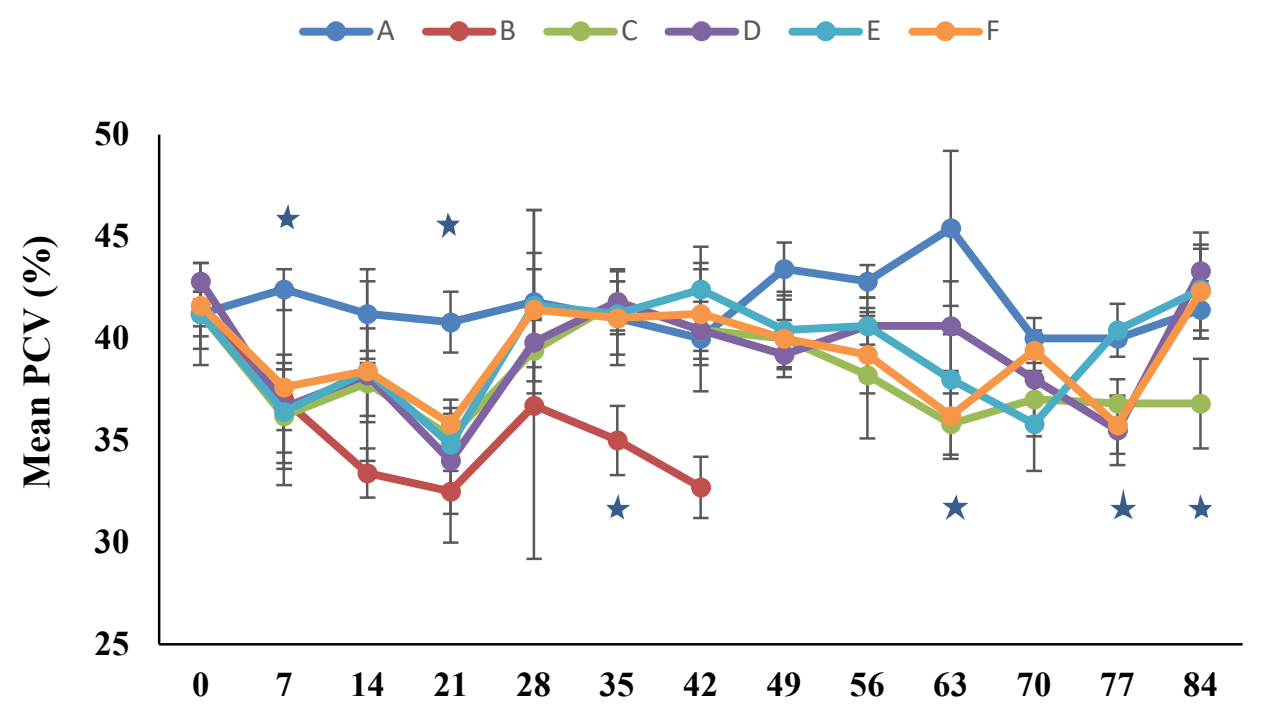

\section{Days Post-infection}

Figure 3: The mean ( $\left.{ }_{\mathrm{S}} \mathrm{SEM}\right)$ packed cell volume (\%) of rats infected with DA-resistant strain $T$. b. brucei and treated with ISM alone and in combination with Na-EDTA, verapamil and chlorpromazine. * significant at $\mathrm{p}>0.05$

A-uninfected, untreated (negative control); B-positive control; C-infected, treated with $1 \mathrm{mg} / \mathrm{kg} \mathrm{ISM}$; D-infected, treated with $1 \mathrm{mg} / \mathrm{kg} \mathrm{ISM}+700 \mathrm{mg} / \mathrm{kg}$ Na-EDTA; E-infected, treated with $1 \mathrm{mg} / \mathrm{kg}$ ISM $+0.4 \mathrm{mg} / \mathrm{kg}$ verapamil; F-infected, treated with $1 \mathrm{mg} / \mathrm{kg}$ ISM $+3 \mathrm{mg} / \mathrm{kg}$ chlorpromazine

Red blood cell count (RBC): The mean RBC counts of rats in the infected groups $\mathrm{B}, \mathrm{C}, \mathrm{D}, \mathrm{E}$ and $\mathrm{F}$ were significantly lower $(\mathrm{P}<0.05)$ by day $7 \mathrm{PI}$, when compared to the corresponding value in negative control group $\mathrm{A}$ (Figure 4). However, by day 14 PI (i.e. 3 day PT), the values of mean RBC count of rats in groups D, E and F (groups treated with drug combination) were not statistically different from that of the negative control while they were significantly higher $(\mathrm{P}<0.05)$ than those of group $\mathrm{C}$ (treated with isometamidium only) and group B (positive control). By day $28 \mathrm{PI}$, the mean RBC count of rats in group $\mathrm{C}$ was not statistically different from rats of other treated groups (D, E and F) and those of negative control. By day 35 , rats in groups $\mathrm{D}, \mathrm{E}$ and $\mathrm{F}$ showed a significantly lower $(\mathrm{P}<0.05)$ mean RBC count when compared to group $\mathrm{C}$ and the negative control (group A), while those of positive control (group B) continued showing a significant decrease $(\mathrm{P}<0.05)$ up to when they were euthanized. By day 42 , rats in groups $\mathrm{C}, \mathrm{D}, \mathrm{E}$ and $\mathrm{F}$ showed a significant lower $(\mathrm{P}<$ $0.05)$ mean $\mathrm{RBC}$ count when compared to the negative control (group A).

Haemoglobin concentration (Hb): The mean $\mathrm{Hb}$ values of rats in the infected groups (B, C, D, E and F) were significantly lower $(\mathrm{P}<0.05)$ by day 7 PI than that of the negative control (group A) (Figure 5). However, by day 14 PI (i.e. 3 days PT), the mean $\mathrm{Hb}$ values of rats in groups $\mathrm{D}$, $\mathrm{E}$ and $\mathrm{F}$ (groups treated with drug combination) were not significantly $(P>0.05)$ different from that of the negative control, while the mean $\mathrm{Hb}$ values in group $\mathrm{C}$ (treated with isometamidium only) and group $\mathrm{B}$ (positive control) remained significantly lower $(\mathrm{P}<0.05)$ when compared with that of the negative control. By day $42 \mathrm{PI}$, rats in group $\mathrm{C}$ showed a significantly higher $(\mathrm{P}<0.05)$ mean $\mathrm{Hb}$ when compared to the corresponding values in rats of groups $\mathrm{D}, \mathrm{E}$ and $\mathrm{F}$ and the negative control, while the mean $\mathrm{Hb}$ in positive control rats (group B) continued to be lower significantly $(\mathrm{P}<0.05)$ up to when they were euthanized. There was a significantly lower $(\mathrm{P}<0.05)$ mean $\mathrm{Hb}$ of rats in groups $\mathrm{C}$ and $\mathrm{F}$ (days 56) and group $\mathrm{D}$ (day 77) and a significantly higher $(\mathrm{P}<0.05)$ mean $\mathrm{Hb}$ of rats in group $\mathrm{C}$ (day 77) when compared with the negative control and other treated groups.

\section{DISCUSSION}

The pre-patent period of 5 days observed in this study falls within the range, 4-5 days, reported by Anene et al. (2006) in rats infected with DA-resistant strain of T. brucei. The level of parasitaemia, which increased slowly but progressively, led to the death of some of the rats on day 35 PI that necessitated euthanasia of the infected untreated rats on day 42 PI. Factors that influence parasitaemia in susceptible animals were documented, which include the number of parasites inoculated (which influences not only the prepatent period but also the height and duration of parasitaemia), inter-current infections, host immune competence, nutritional status, and the pathogenicity of the strain of T. brucei brucei (Taylor and Authie, 2004). 


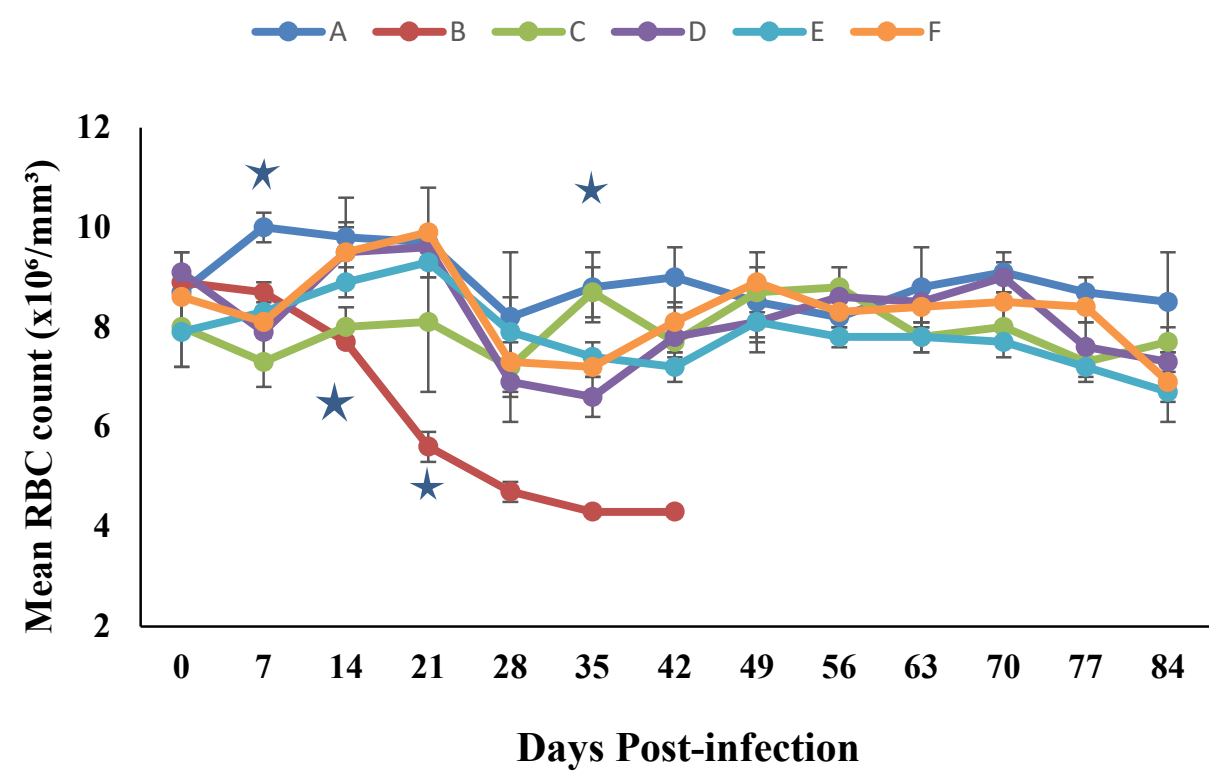

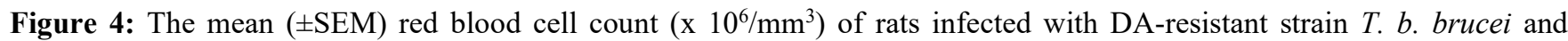
treated with ISM alone and in combination with Na-EDTA verapamil and chlorpromazine. * significant at $\mathrm{p}>0.05$

A-uninfected, untreated (negative control); B-positive control; C-infected, treated with $1 \mathrm{mg} / \mathrm{kg} \mathrm{ISM}$; D-infected, treated with $1 \mathrm{mg} / \mathrm{kg} \mathrm{ISM}+700 \mathrm{mg} / \mathrm{kg} \mathrm{Na}-E D T A ;$ E-infected, treated with $1 \mathrm{mg} / \mathrm{kg} \mathrm{ISM}+0.4 \mathrm{mg} / \mathrm{kg}$ verapamil; F-infected, treated with $1 \mathrm{mg} / \mathrm{kg}$ ISM $+3 \mathrm{mg} / \mathrm{kg}$ chlorpromazine

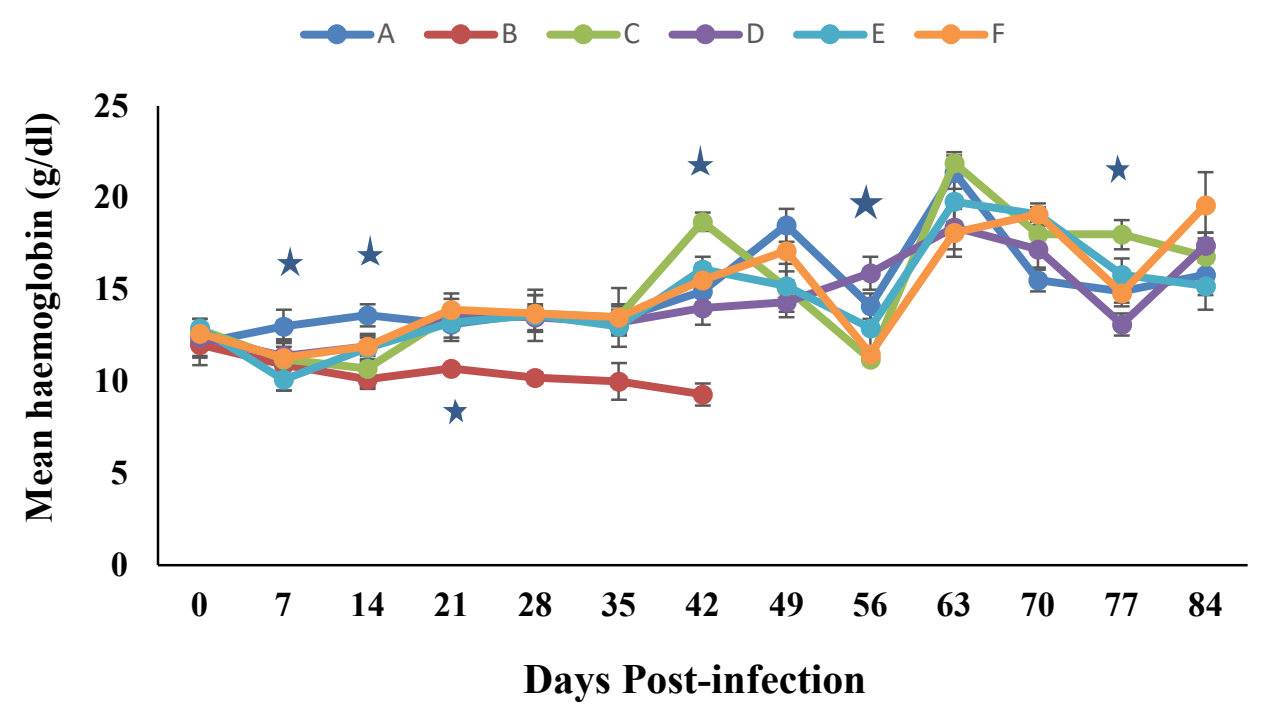

Figure 5: The mean $( \pm \mathrm{SEM})$ haemoglobin concentration $(\mathrm{g} / \mathrm{dl})$ of rats infected with DA-resistant strain T. b. brucei and treated with ISM alone and in combination with Na-EDTA, verapamil and chlorpromazine. * significant at $\mathrm{p}>0.05$

A-uninfected, untreated (negative control); B-positive control; C-infected, treated with 1mg/kg ISM; D-infected, treated with $1 \mathrm{mg} / \mathrm{kg} \mathrm{ISM}+700 \mathrm{mg} / \mathrm{kg}$ Na-EDTA; E-infected, treated with $1 \mathrm{mg} / \mathrm{kg} \mathrm{ISM}+0.4 \mathrm{mg} / \mathrm{kg}$ verapamil; F-infected, treated with $1 \mathrm{mg} / \mathrm{kg}$ ISM $+3 \mathrm{mg} / \mathrm{kg}$ chlorpromazine

The clinical signs observed such as, rough hair coat, pale mucous membrane dullness, decreased feed intake in the infected groups were typical of those reported of the trypanosomosis. The high temperature observed, which corresponded with the period of parasitaemia (Taylor and Authie, 2004; Adieme et al., 2014). Significant funding in this study is that clearance of parasites PT varied among the treatment combinations. Groups treated with Sodium-EDTA and with verapamil combinations had $100 \%$ clearance rate by 24 hours PT. This parasitological evaluation is a measure, which could be used as an index for assessing efficacy of treatment of trypanosomosis in addition to the return of haematological values to pre-infection values (Dina et al., 2002). Thus, verapamil and sodium-EDTA combination with isometamidium could be said to have a better effect when compared with other treatment regimes. 
EDTA has been reported to disrupt the lipopolysacharide structure in the outer membrane of cells resulting in the membranes becoming more permeable to more isometamidium molecules and hence potentiating the action of isometamidium (Haque and Russell, 1974). Ihedioha et al. (2007) also reported from his study, a slight potentiation of diminazene aceturate (in the treatment of mice infected with DA-resistant $T$. brucei) when co-administered with Sodium-EDTA and that the administration of SodiumEDTA alone significantly enhanced the resistance of the infected mice. Similarly, Anene et al. (1996) demonstrated in an in vitro study the anti-trypanosmal activity of verapamil and chlopromazine. From our observation also, group treated with chlorpromazine combination had $80 \%$ clearance by 24 hours PT. It has also been reported that many tricyclic compounds have anti-trypanosomal and antileishmanial activity of which chlorpromazine was found to be the most potent (Benson et al., 1992). The activity of chlorpromazine is said to arise from its selective inhibition of trypanothione reductase interference with micro-tubule assembly and proton based electrochemical gradient membrane disruption (Hammond et al., 1985).

The significant body weight change observed in the infected untreated rats is consistent with other reports that trypanosomosis cause loss of weight (Adieme et al., 2014). This may be attributed to anorexia and dullness, and thus decreased feed intake observed. However, a continuous but gradual increase in the mean proportional weight changes was observed in the treated groups despite the relapse of parasitaemia post-clearance when compared with the uninfected untreated control. It has also been found that weight changes in trypanosomosis are markedly influenced by the levels of protein intake, and high intake allows infected animals to grow at same rate as uninfected controls provided energy intake is adequate whilst low energy levels can exacerbate the adverse effects of trypanosomosis on body weight (Holmes et al., 2000; Chukwudi et al., 2016). Thus, the gradual increase in proportional weight change seen may be attributed to the chronic nature of the infection at this stage and, also may be due to the fact that the rats were on good nutrition with high quality protein in the diet which helped in overcoming the weight loss associated with trypanosomosis.

Anaemia observed as decreased in the erythrocyte parameters $(\mathrm{PCV}$, haemoglobin concentration and $\mathrm{RBC}$ values) is the prominent feature of animal trypanosomosis (Taylor and Authie, 2004) and has been reported by so many authors (Anene et al., 2006; Adieme et al., 2014). Following treatment, the anaemia was reversed in all the treated groups. But following relapse of parasitaemia which was low (average log 6.55), the erythrocytic parameters did not differ from the negative control. This may be attributed to the chronic nature of the infection at this stage. Chronic phase of trypanosomosis has been reported to be characterised by low level of parasitaemia, which persists with minor fluctuation in the erythrocytic value (Mbaya et al., 2012).

Relapse of infection observed in all treated groups may be attributed to the parasite return to the vascular system after the effect of the drug had waned. Relapse infection has been explained to occur due to drug resistance and also due to migration of the parasites into the brain tissue where drug could not affect them (Anene et al., 2001; Geerts et al., 2001). Jennings et al. (1977) established an inverse relationship between the duration of infection and the occurrence of relapse. Relapse infection observed in early treatment (between day 3-7 PI) could be due to drug resistance while in late treatment (from day $14 \mathrm{PI}$ ) could be due to the reappearance of parasites that had migrated into the brain tissue where they were inaccessible to the drugs (Akpa et al., 2008). Treatment in this study was done on day $11 \mathrm{PI}$, and also DA-resistant strain of T.b brucei was the infecting parasite. Thus, relapse infection could be attributed to both the reappearance of parasite, which may have been sequestered in the brain and the DA-resistant strain of parasite. A study by Eisler et al. (1993) showed that isometamidium serum concentration has a half-life of approximately 25 days while another study Eisler (1996) indicated an elimination half-life 9-19 days. Groups treated with Sodium- EDTA and verapamil were the last to relapse on day 39 PT (i.e. day 50 post infection) while groups treated with chlorpromazine combination relapsed on day 37 PT. This agrees with the reports of earlier studies that verapamil did not reverse resistance of $T$. brucei to diminazene or isometamidiumin vitro or in vivo (Kaminsky and Zweygarth, 1991) or of T. evansi to suramin, berenil or melCy (Anene et al., 1996). It is in contrast with the findings of Neal et al. (1989) and Dey et al. (1994), who reported a reversal of drug resistance in $T$. cruzi and Leishmania spp by verapamil and also Sutherland et al. (1991) who reported that co-administration of verapamil effectively blocked isometamidium chloride efflux from resistant $T$. congolense infection. Although it has been reported that mutation in an important mitochondrial protein can strongly reduce mitochondrial membrane electrical potential and this could result in isometamidium resistance thus leading to high levels of resistance and even crossresistance to various drugs (Eze et al., 2016). Active extrusion of drugs leading to reduced accumulation of drugs in resistant parasites when compared with drug sensitive organisms has been reported to be one mechanism associated with trypanocidal resistance (Yarlett et al., 1991; Sutherland and Holmes, 1993).

In conclusion, treatment of diminazene aceturate-resistant strain of Trypanosoma brucei brucei infection using isometamidium in combination with EDTA or verapamil were able to effectively facilitate the clearance of the parasites from the blood and, also were able to delay relapse of parasitaemia post-clearance.

\section{Conflict of Interest}

The authors declare that they do not have any conflict of interest.

\section{Authors Contribution}

CIC and ABM contributed to the study conception and design. Material preparation, data collection, and analysis were performed by all authors. All authors read and approved the final manuscript. 


\section{REFERENCES}

Abimbola, A.N., Baba, I.A., Yenusa, E.Z., Omanibe, S.J. and Oladimeji, I.H. (2013). Anti-Trypanosoma effect of peristrophebicalyculataectract on Trypanosoma brucei brucei infected rats. Asian Pac. J. Trop. Biomed., 3: 523-531

Adieme, I.C, Ezeh, I.O., Ugochukwu, E.I. and Ezeokonkwo, R.C. (2014). Effect of diminazine aceturate, levamisole and vitamin $\mathrm{C}$ combination therapy in rats experimentally infected with Trypanosome brucei brucei. Asian Pac. J. Trop. Med., 7(6): 438445

Akpa, P.O., Ezeokonkwo, R.C., Eze, C.A. and Anene, B.M. (2008). Comparative efficacy assessment of pentamidine isethionate and diminazene aceturate in the chemotherapy of Trypanosoma brucei infection in dogs. Vet. Parasitol., 151(2-4): 139149

Anene, B.M., Ezeokonkwo, R.C., Mmesirionye, T.I., Tettey, J.N.A., Brock, J.M. and Barret, M.P. (2006). Diminazene Resistant strain of Trypanoso ma brucei isolated from a dog in cross resistant to Pentamidium in experimentally infected albino rats. Parasitol., 132:127-133

Anene, B.M., Onah, D.N. and Nawa, Y. (2001). Drug resistance in pathogenic African Trypanosomes: What hopes for the future? Vet. Parasitol.,96(2): 83-100

Anene, B.M., Ross, C.A., Anika, S.M. and Chukwu, C.C. (1996). Trypanocidal resistance in Trypanosoma evansi in vitro: effects of Verapermil, Cyproheptidine, Desipramine and Chlorpromazine alone and in combination with trypanocides. Vet. Parasitol., 62: 43-50

Baker, N., de Koning, P., Maser, P., Hom, D. (2013) Drug resistance in African trypanosomiasis: the melarsopol and pentamidine story. Trends Parasitol., 29(3): 10.1016/j.pt.2012.12.005

Benson, T.J., McKie, J.H., Garforth, J., Borges, A., Fairlamb, A.H. and Douglas, K.T. (1992). Rationally designed inhibitors of trypanothoine reductase: phenothiazines and related tricyclics as lead structures. Biochem. J.,286: 9-11

Boyt, W.P. (1984). A Field Guide for Diagnosis, Treatment and Prevention of African Animal trypanosomosis. FAO, Rome.Pp88-119

Chukwudi, I.C., Anene, B.M., Chukwu, C.C., Ezeh, I.O and Ogbu, K.I. (2016). Effect of Peste des Petits Ruminants vaccination on clinico-haematological parameters of West African Dwarf sheep experimentally infected with Trypanosoma congolense. Annu. Res. Rev. Biol., 9(6): 1-13, doi: 10.9734/ARRB/2016/23671ISSN: 2347-565X, NLM ID: 101632869

Dacie, J.V. and Lewis, S.W. (1999). Practical haematology ( $7^{\text {th }}$ edition) ELBS with Churchill Livingstone, London. pp.37-85

Delespaux, V. and de Koning, H.P. (2007). Drug and drug resistance in African trypanosmiasis. Drug Resist. Updat., 10: 30-50
Dey, S., Papadopoulou, B., Haimeur, A., Roy, G., Grondin, K., Dou, D., Rosen, B.P. and Ouellette, M. (1994). High level arsenite resistance in Leishmania tarentolae is mediated by an active extrusion system. Mol. Biochem. Parasitol.,67(1):49-57 do.10.1016/0166-6851(94)900957 PMID:7838183.

Dina, O.A., Saba, A.B., Adedapo, A.A., Akinyemi, O.A. and Omobowale, T.O. (2002). Comparative efficacy study of humidium bromide, diminazene aceturate and their combination in New Zealand white rabbits experimentally infected with Trypanosoma congolense. Trop. Vet., 20(3): 153158

Duncan, O.D. (1996). Path analysis: sociological examples. Amer. J. Soc.,72: 1-16

Eisler, M.C., Brandt, J., Bauer, B., Clausen, P.H., Delespaux, V., Holmes, P.H., Ilemobade, A., Machila, N., Mbwambo, H., Mc Dermott, J., Mehlitz, D., Murilla, G., Ndung'u, J.M., Peregrine, A.S., Sidibe, I., Sinyangwe, L. and Geerts, S. (2001). Standardised tests in mice and cattle for the detection of drug resistance in tsetse-transmitted trypanosomes of African domestic cattle. Vet. Parasitol., 97: 171-183

Eisler, M.C. (1996). Pharmacokenetics of chemoprophylacti c and chemotherapeutic trypanocidal drug isometamidium chloride (samorin) in cattle. Drug Metab. Dispos., 24: 1355- 1361

Eisler, M.C., Gault, E.A., Smith, H.V., Peregrine, A.S. and Holmes, P.H. (1993). Evaluation and improvement of enzyme-linked immunosorbent assay (ELISA) for the detection of Isometamidium in bovine serum. Ther. Drug Monit., 15: 236-242

Eze, A.A., Gould, M.K., Munday, J.C., Tagoe, D.N.A., Stelmanis, V., Schnaufer, A. and De Koning, H.P. (2016). Reduced Mitochondrial Membrane Potential Is a Late Adaptation of Trypanosoma brucei brucei to Isometamidium Preceded by Mutations in the $\gamma$ Subunit of the $\mathrm{F}_{1} \mathrm{~F}_{\mathrm{o}}$-ATPase. PLoS Negl Trop. Dis., 10(8): e0004791 https://doi.org/10.1371/journal.pntd.0004791

Geerts, S., Holmes, P.H., Eisler, M.C. and Oiall, O. (2001). African bovine trypanosomiasis: The problem of drug resistance. Trends Parasitol., 17: 25-28

Giordani, F., Morrison, L.J., Rowar, T.G., de Koning, H.P., Baret, M.P. (2016). The animal trypanosomiases and their chemotherapy: a review. Parasitol., 143(14): 1862-1889

Gottesman, M.M. and Pasten, I. (1998). Resistance to multiple chemotherapeutic agents in human cancer cells. Trends Pharmacol. Sci., 9: 54-58

Hammond, D.J., Hogg, J. and Gutteridge, W.E. (1985). Trypanosoma cruzi: possible control of parasite transmission by blood transfusion using amphiphilic cationic drugs. Exp. Parasitol., 60: 3242

Haque, H. and Russell, A.D. (1974). Effect of chelating agents on the susceptibility of some strains of Gram-negative bacteria to some antibacterial agents. Antimicrob. Agents Chemother., 6(2): 200206. 
Holmes, P.H., Katunguka-Rwakishaya, E., Bennison, J.J., Wassink, G.J. and Parkins, J.J. (2000). Impact of nutrition on the pathophysiology of bovine trypanosomiasis. Parasitol., 120 (suppl.): 73-85

Ihedioha, J.I., Ochiogu, I.S. and Ihedioha, T.E. (2007). Coadministration of Na-EDTA and diminazene aceturate (DA) to mice infected with DA-resistant Trypanosoma brucei. J. Comp. Pathol., 136(23):206-211, doi:10.1016/j.jcpa.2007.01.003

Jennings, F.W., Whitelaw, D.D. and Urquhart, G.M. (1977). The relationship between the duration of infection with $T$. brucei in mice and the efficacy of chemotherapy. Paraistol., 75: 145-153

Kaminsky, R. and Zweygarth, E. (1991). The effect of verapamil alone and in combination with Trypanocides on multidrug resistant Trypanosoma brucei brucei. Acta. Trop., 49: 215-225

Mamoudou, A., Delespaux, V., Chepnda, V., Hachimou, Z., Andrikaye, J.P., Zoli, A. and Geerts, S. (2008). Assessment of the occurrence of trypanocidal drug resistance in trypanosomes of maturely infected cattle in the Adamaoua region of Cameroon using the standard mouse test and molecular tools. Acta. Trop.,106(2): 115-118 doi.10.1016/j.actatropica.20 08.02.003

Mbaya, A., Kumshe, H., Nwosu, C.O. (2012). The mechanism of anaemia in trypanosomosis. A review. 269-282. In: Anaemia, Dr. Donald Silverberg (Ed), ISBN:978-953-51-0138-3, In Tech, Available from http://www.intechopen.com/ books/anaemia/the mechanisms-of-anaemia-intrypanosmosis-a-review.

Mier, A., Erier, H. and Beitz, E. (2018). Targeting Channels and Transporters in Protozoan Parasite Infections. Front. Chem., 6: 88. dio:10.3389/fchem.2018.0008 8

NASA (National Aeronautics and Space Administration) (2008). NASA Principles for the Ethical Care and Use of Animals. NPR 8910.1B-Appendix A. May 28. Available at http://nodis3. gsfc.nasa.gov/displa yDir.cfm?t=NPDandc=8910ands $=1 B ; \quad$ accessed May 10, 2010.

Neal, R.A., Van Bueren, J., McCoy, N.G. and Iwobi, M. (1989). Reversal of drug resistance in Trypanosoma cruzi and Leishmania donovani by verapamil. Trans. R. Soc. Trop. Med. Hyg., 83: 197-198
Oduola, A.M.J., Sowunmi, A., Milhous, W.K., Brewer, T.G., Kyle, D.E., Gerena, L., Rossan, R.N., Salako, L.A. and Scuster, B.G. (1998). In vitro and in vivo reversal of chloroquine resistance in Plasmodium falciparum with promethazine. Am. J. Trop. Med. Hyg., 58(5): 625-629 doi.10.4269/ajtmh.1998.58.62 5

Onyeyili, P.A. and Aliyoo, K. (2015). In vitro and in vivo evaluation of antitrypanosomal activity of Annonna muricata stem bark extracts. Herba Pol., 61(2): 5062

Ramirez Campos, M. and Villafuerte Robles, L. (2004). Effect of formulation variables on verapamil hydrochloride release from hydrated HPMC matrices. J. Mex. Chem. Soc.,48: 326-331

Rickman, L.R. and Robson, J. (1970). The blood incubation infectivity test: a simple test which may distinguish Trypanosma brucei from $T$.rhodesiense. Bull. Wld. Hlth. Org., 42: 650-651

Schalm, O.W., Jain, N.C. and Carrol, E.J. (1975). Veterinary Haematology 3rd edn. Lea and Febiger, Philadelphia. 15-81

Sonibare, A.O.., Famuyide, I.M., Takeet, M.I., Oyewusi, I.K., Egbetade, A.O., Abapka, S.A.V., Adeniran, O.A. and Solanke, A.O. (2016). Diminazeneresistant Trpanosoma vivax in West African dwarf lamb, South-West, Nigeria: a case report. Nig. J. Parasitol., 37: 62-65

Soulsby, E.J.I. (1986). Helminths, Arthropods and Protozoa of Domestic Animals. 8th Edition. London. Balliere Tindall, London. pp. 203-206

Sutherland, I.A. and Holmes, P.H. (1993). Alterations in drug transportation resistant Trypanosoma congole nse. Acta. Trop., 54:271-278

Sutherland, I.A., Peregrine, A.S., Lonsdale-Eccle, J.D. and Holmes, P.H. (1991). Reduced accumulation of Isometamidium by drug-resistant Trypanosoma congolense. Parasitol., 103: 245 - 251

Taylor, K. and Authie, E.M. (2004). Pathogenesis of Animal Trypanosomosis, In: Maudlin, I.; Holmes, P. H. and Miles, M. A. (Eds) The Trypanosomiasis. CAB International Wallingford UK. pp. 331-353

Yarlett, N., Goldberg, B., Nathan, H.C., Garofalo, J. and Bacchi, C. (1991). Differential sensitivity of Trypanosoma brucei rhodesiense isolates to in vitro lysis by arsenicals. Exp. Parasitol., 72: 205215 